\title{
Optimization of HPLC Using Central Composite Design for Determination of Curcumin and Demethoxycurcumin in Tablet Dosage Form
}

\author{
Chairany Siregar ${ }^{1,2}$, Niken K. Prabaningdyah ${ }^{3}$, Syaiful Choiri ${ }^{1}$, \\ Sugeng Riyanto ${ }^{1}$ and Abdul Rohman ${ }^{4}$ \\ ${ }^{1}$ Faculty of Pharmacy, GadjahMada University, Yogyakarta, 55281, Indonesia \\ ${ }^{2}$ The National Agency of Drug and Food Control, District of Samarinda, East Kalimantan, \\ Republic of Indonesia \\ ${ }^{3}$ The National Agency of Drug and Food Control, District of Yogyakarta, Republic of Indonesia \\ ${ }^{4}$ Research Center of Halal Products, GadjahMada University, Yogyakarta, 55281, Indonesia
}

(Received: October 29, 2017; Accepted: November 30; Published (web): December 23, 2017)

\begin{abstract}
In this study, central composite design (CCD) was used for optimization of high performance liquid chromatographic (HPLC) method for simultaneous analysis of curcumin (CUR) and demethoxycurcumin (DMC) in tablets containing Curcuma extract. Separation of CUR and DMC was performed using X-Bridge $\mathrm{C}_{18}$ column ( $250 \mathrm{x}$ $4.6 \mathrm{~mm}$ i.d; $5 \mu \mathrm{m}$ ). Four factors that were investigated include the concentration of acetic acid (X1), ratio of acetic acid (X2), flow rate of mobile phase (X3) and column temperature (X4). Based on responses obtained (retention time, peak area, resolution and tailing factor), the optimum condition selected was $\mathrm{X} 1=3.00 \%, \mathrm{X} 2=51 \%, \mathrm{X} 3=1.05$ $\mathrm{mL} / \mathrm{min}$ and $\mathrm{X} 4=45 \mathrm{oC}$. This HPLC condition was validated by assessing several validation parameters including system suitability test, selectivity, linearity, precision, accuracy and robustness according to International Conference Harmonization (ICH). All validation parameters meet the acceptance criteria set by ICH. The validated method was successfully used for analysis of CUR and DMC in tablets containing Curcuma extract. CCD was effective means in optimization of HPLC for analysis of CUR and DMC in pharmaceutical formulation.
\end{abstract}

Key words: Curcumin, demethoxycurcumin, central composite design, optimization.

\section{INTRODUCTION}

Curcuma xanthorrhiza known as Temulawak is a representative of Indonesian traditional medicine and commonly used as hepatoprotective and antioxidant. ${ }^{1}$ The main active components in temulawak include curcuminoids, monoterpenoids and sesquiterpenoids such as xanthorrizol, bisacurol, bisacumol, and bisacurone. ${ }^{2}$ Curcumin (CUR) and demethoxycurcumin (DMC) belong to curcuminoids as pharmacologically active compounds. The chemical structures of CUR and DMC are shown in figure 1. Both curcuminoids have been reported to exhibit strong anti-oxidant, ${ }^{1}$ anti-inflammatory, ${ }^{3}$ antibacterial

Correspondence to: Abdul Rohman

Email: abdul_kimfar@ugm.ac.id

Phone: $+62274-543120$

Dhaka Univ. J. Pharm. Sci. 16(2): 137-145, 2017 (December) and antifungal activities. ${ }^{4,5}$ Therefore, determination of CUR and DMC in pharmaceutical formulation such as tablets is important to assure the biological activities of pharmaceutical formulation containing Curcuma extract.

Several methods have been reported for analysis of curcuminoids namely near infrared spectroscopy ${ }^{5}$, mid infrared spectroscopy ${ }^{6}$, thin layer chromatography-densitometry ${ }^{7}$, high performance liquid chromatography using UV-visible ${ }^{8,9}$ electrochemical detectors ${ }^{10}$ and liquid chromatography-mass spectrometry. ${ }^{11}$ HPLC is a method of choice for analysis of curcuminoids due to its capability to provide good separation among curcuminoids. Some parameters such as composition of mobile phase, flow rate, column temperature influenced HPLC separation, indeed, the optimization 
of these parameters are required to get optimum separation.

Design of experiments (DoE) is the simple method used for optimization several factors (variables) affecting HPLC separation of analytes. ${ }^{13,14}$ Several studies related to the use of DoE in analysis of curcumin were carried out. Paulucci et al. ${ }^{15}$ used full factorial design and the response surface methodology for optimization of curcumin extraction from Curcuma longa rhizomes. Central composite rotatable design was used for optimization of curcumin extraction using four independent variables namely temperature, particle size, mixing time, and solvent to meal ratio. ${ }^{16}$ Avram et al. ${ }^{17}$ used BoxBehnken Design to investigate the effects of temperature, extraction time and liquid/solid ratio for evaluation of extraction efficiency. To the best of our knowledge, there is no reports regarding the use of CCD for HPLC optimization condition in analysis of CUR and DMC in tablet formulation. In this study, CCD was explored for optimization of HPLC condition to separate CUR and DMC in tablet dosage form containing curcuma extract. Separation of CUR and disage form DMC was performed using $\mathrm{X}$ Bridge $\mathrm{C}_{18}$ column $(250 \times 4.6 \mathrm{~mm}$ i.d; $5 \mu \mathrm{m})$.

\section{MATERIALS AND METHODS}

Curcuminoid standard was obtained from E. Merck (Darmstadt, Germany). Curcumin (CUR) and demethoxycurcumin (DMC) (Figure 1) were isolated from standard curcuminoid using column chromatography as reported by Péret-Almeida et $\mathrm{al}^{7}$ In order to evaluate the purity, both CUR and DMC were subjected to thin layer chromatography and HPLC. The solvents used for analysis were of HPLC grade while other solvents and reagents were of proanalytical grade, unless otherwise was specified. Tablet samples containing Curcuma xanthorrhiza were purchased from several pharmacy around Yogyakarta, Indonesia.

Method optimization. Central composite design (CCD) is used in HPLC method development and optimization. Selection of mobile phase-related factors and column temperature during HPLC optimization is important in analytical method development; therefore some factors were considered namely concentration of acetic acid (X1), ratio of acetic acid (X2), flow rate of mobile phase (X3) and column temperature (X4). CCD was selected to give complete response under extreme conditions (highest or lowest levels of independent variables) which is not possible obtained using Box-Behnken design. ${ }^{18}$ CCD was carried out using Design Expert (Version 10 (Trial Version), Stat-Ease Inc., Minneapolis, MN USA). Thirty experiments were constructed using four variables (X1, X2, X3 and X4) along with observed responses as described in table 1. Peak purity in one of CCD experiments was shown in figure 2 .

HPLC instrumentation. HPLC instrument- LC20AD (Shimadzu, Japan) equipped with injector valve of Rheodyne $7725 \mathrm{i}$ with a $20 \mu \mathrm{l}$ loop volume and binary gradient pump was used. The system also included photodiode array (Shimadzu, SPD-M20A) delector. Data were acquired and processed using LC-solution software. Chromatographic separation was performed using Waters ${ }^{\circledR}$ X-Bridge $(250 \times 4.6$ $\mathrm{mm}$ i.d., $5 \mu \mathrm{m}$ ). For initial HPLC analysis, the mobile phase of acetonitrile-acetic acid in aquadest (50: 50 $\mathrm{v} / \mathrm{v}$ ) delivered isocratically at $1.0 \mathrm{ml} / \mathrm{min}$ was used. PDA detector was set at $425 \mathrm{~nm}$ in which both drugs gave good response, injection volume was kept at 20 ul.

System suitability test. Before validation of HPLC method, system suitability test (SST) was performed by six replicate injections of working standard solutions. The parameters evaluated include retention time, peak area, tailing factor, efficiency and height equivalent to the theoretical plate (HETP). SST was evaluated based on precision of HPLC condition for intended analysis. The $\%$ relative standard deviation (\% RSD) of each set of parameters (retention time, peak area, tailing factor, efficiency and HETP) should be less $<2 \% .18$

Validation of HPLC method. HPLC using optimized condition was validated according to recommendation from International Conference on Harmonisation (ICH) by assessing for specificity, 
accuracy, precision, sensitivity expressed by limit of detection (LOD) and limit of quantitation (LOQ), robustness and ruggedness. ${ }^{19}$

Selectivity test. The selectivity of optimized HPLC method was evaluated by comparing chromatograms obtained from analysis of solvent, standard solutions of CUR and DMC, and sample solution produced by dissolving commercial formulation. The method was selective if peaks observed in the chromatograms were well separated and there were no co-eluting peaks at retention times of CUR and DMC. Using diode array detector (DAD), peak purity index was evaluated using LCsolution software. If the purity angle is smaller than the purity threshold, co-elution is evident and the peak of analytesis considered to be pure.20 In addition, HPLC is selective if resolution value of analytes (CUR and DMC) was $\geq 2.0$.

Linearity and sensitivity. The linearity of optimized HPLC method was evaluated by fitting calibration data using least squares regression with eight different concentrations of CUR (0.583-23.311 $\mu \mathrm{g} / \mathrm{ml})$ and DMC $(0.109-4.348 \mu \mathrm{g} / \mathrm{ml})$. The calibration curves were established by plotting peak area (y-axis) against concentration of CUR and DMC (x-axis). The linearity was evaluated using correlation coefficient (r-value) and intercept value. The values of LoD and LoQwere calculated as:

$\mathrm{LoD}=3.3 \times \mathrm{Sa} / \mathrm{b}$ and $\mathrm{LoQ}=10 \times \mathrm{Sa} / \mathrm{b}$; where $\mathrm{Sa}$ is standard deviation of intercept and $b$ is slope of calibration curve.

Precision and accuracy. To judge the quality of analytical method in terms of investigating random and systematic errors, the precision and accuracy of developed method were evaluated. Precision of HPLC method was evaluated through repeatability test by injecting six replicates of homogenous tablet sample. The value of coefficient variation (CV) was used to evaluate precision. In addition, the accuracy of method was evaluated by spiking standards of CUR and DMC in predetermined tablet solution at three different concentration levels (80, 100 and $120 \%$ from target value), and calculating the percent recovery of active ingredient.
Assay of tablet sample. Ten tablets were accurately weighed and powdered separately. A portion of powder equivalent to $3 \mathrm{mg}$ of CUR and 0.2 DMC was transferred to volumetric flask $(100 \mathrm{ml})$ and dissolved in about $50 \mathrm{ml}$ of mobile phase. The sample solution was sonicated for $20 \mathrm{~min}$ using ultrasonic bath and diluted to the mark with mobile phase. The solution was filtered using $0.45 \mu \mathrm{m}$ membrane filter. The working solutions containing concentrations of CUR and DMC were prepared by dilution using mobile phase, and $20 \mu \mathrm{l}$ of filtered solution was injected in HPLC system.

\section{RESULTS AND DISCUSSION}

HPLC condition optimization. The design experimental of central composite design (CCD) was performedusing 30 experimental runs. The levels of independent variables namely concentration of acetic acid (\%) (X1), \% ratio of acetic acid (X2), flow rate (X3) and column temperature (X4) along with reponses or dependent variables of retention time (Y1), peak area (Y2), resolution (Y3) and tailing factor (Y4) are shown in table 1. The proposed model for Y1 was:

$\frac{1}{\sqrt{Y 1}}=0.36+2.065 \times 10-3 \mathrm{X} 1-0.057 \mathrm{X} 2+0.035 \mathrm{X} 3$ $+7.948 \times 10-3 \mathrm{X} 4+7.218 \times 10-4 \mathrm{X} 1 \mathrm{X} 2+4.808 \times 10-$ $4 \mathrm{X} 1 \mathrm{X} 3+6.501 \times 10-5 \mathrm{X} 1 \mathrm{X} 4-6.236 \times 10-3 \mathrm{X} 2 \mathrm{X} 3$ $+4.109 \times 10-4 \mathrm{X} 2 \mathrm{X} 4+9.085 \times 10-4 \mathrm{X} 3 \mathrm{X} 4-2.465 \times$ 10-3X12 -3.158 x 10-3X22 -1.224 x 10-3X32+1.040 x 10-3X42 (Adj. R2 of 0.9975) (Eq. 1)

The selection of the best fit model to describe the effect and interaction on the responses was based on some criteria, namely significant model $(\mathrm{p}<0.05)$, not significant lack of fit ( $p>0.05$ ), R2 more than 0.7, and the difference between Adj. R2 and Pred. R2 less than 0.2.21 All models had significant term, while only the peak area response had not significant lack of fit. A significant lack of fit must be considered, particularly the difference between Adj. R2 and Pred $\mathrm{R} 2$. The value of $\mathrm{R} 2$ was used for navigating the optimized condition. The coefficients for the model were estimated by least squares regression. Generally, the positive value in equation indicated 
the favorable response, while a negative value indicated an inverse relationship between independent variables and the response. In addition, the transformation of experimental model must be considered to explain the main effects and interactions accurately. Furthermore, an inverse model transformation means the higher coefficient the lower effect on main effects or interactions and vice versa. ${ }^{14}$

Table 1. Central composite design using four independent variables for HPLC optimization during analysis of curcumin and demethoxycurcumin in tablet along with responses obtained.

\begin{tabular}{|c|c|c|c|c|c|c|c|c|}
\hline Run & $\begin{array}{l}\text { Concentration of } \\
\text { acetic acid (\%) } \\
\text { (X1) }\end{array}$ & $\begin{array}{l}\text { \%ratio of } \\
\text { acetic acid } \\
\text { (X2) }\end{array}$ & $\begin{array}{c}\text { Flow rate } \\
\text { (X3) }\end{array}$ & $\begin{array}{l}\text { Column } \\
\text { temperature } \\
\text { (X4) }\end{array}$ & $\begin{array}{l}\text { Retention } \\
\text { time (Y1) }\end{array}$ & $\begin{array}{c}\text { Peak are } \\
\text { (Y2) }\end{array}$ & $\begin{array}{l}\text { Resolution } \\
\text { (Y3) }\end{array}$ & $\begin{array}{l}\text { Tailing } \\
\text { factor } \\
\text { (Y4) }\end{array}$ \\
\hline 1 & 2 & 50 & 1 & 35 & 7.819 & 258138 & 2.518 & 1.192 \\
\hline 2 & 1 & 55 & 0.8 & 30 & 15.136 & 331658 & 3.089 & 1.154 \\
\hline 3 & 2 & 50 & 1 & 35 & 7.799 & 258073 & 2.516 & 1.202 \\
\hline 4 & 2 & 50 & 0.6 & 35 & 12.776 & 412383 & 2.776 & 1.2 \\
\hline 5 & 2 & 50 & 1 & 35 & 7.785 & 258506 & 2.513 & 1.203 \\
\hline 6 & 1 & 55 & 0.8 & 40 & 13.52 & 294285 & 3.556 & 1.171 \\
\hline 7 & 3 & 45 & 0.8 & 40 & 6.946 & 311603 & 2.08 & 1.28 \\
\hline 8 & 1 & 55 & 1.2 & 30 & 10.401 & 216013 & 2.89 & 1.143 \\
\hline 9 & 4 & 50 & 1 & 35 & 8.38 & 253461 & 2.685 & 1.181 \\
\hline 10 & 3 & 45 & 1.2 & 30 & 5.032 & 221032 & 1.757 & 1.237 \\
\hline 11 & 2 & 50 & 1.4 & 35 & 5.622 & 187188 & 2.356 & 1.172 \\
\hline 12 & 1 & 45 & 0.8 & 40 & 7.09 & 316057 & 2.114 & 1.287 \\
\hline 13 & 2 & 50 & 1 & 35 & 7.778 & 255730 & 2.516 & 1.201 \\
\hline 14 & 3 & 45 & 0.8 & 30 & 7.452 & 322233 & 1.939 & 1.253 \\
\hline 15 & 1 & 45 & 0.8 & 30 & 7.633 & 324034 & 1.944 & 1.259 \\
\hline 16 & 3 & 55 & 0.8 & 40 & 12.866 & 283239 & 3.515 & 1.155 \\
\hline 17 & 1 & 45 & 1.2 & 30 & 5.151 & 219251 & 1.771 & 1.239 \\
\hline 18 & 1 & 45 & 1.2 & 40 & 4.786 & 214071 & 1.96 & 1.244 \\
\hline 19 & 2 & 40 & 1 & 35 & 4.789 & 254585 & 1.51 & 1.315 \\
\hline 20 & 3 & 55 & 0.8 & 30 & 14.391 & 305456 & 3.091 & 1.153 \\
\hline 21 & 2 & 50 & 1 & 45 & 7.094 & 236630 & 2.766 & 1.2 \\
\hline 22 & 2 & 60 & 1 & 35 & 19.055 & 228006 & 3.957 & 1.116 \\
\hline 23 & 1 & 55 & 1.2 & 40 & 9.26 & 202102 & 3.37 & 1.145 \\
\hline 24 & 2 & 50 & 1 & 35 & 7.803 & 251270 & 2.522 & 1.198 \\
\hline 25 & 2 & 50 & 1 & 35 & 7.799 & 251050 & 2.53 & 1.199 \\
\hline 26 & 0 & 50 & 1 & 35 & 8.346 & 250243 & 2.525 & 1.348 \\
\hline 27 & 3 & 55 & 1.2 & 40 & 8.772 & 214209 & 3.329 & 1.136 \\
\hline 28 & 3 & 55 & 1.2 & 30 & 9.832 & 227196 & 2.868 & 1.134 \\
\hline 29 & 2 & 50 & 1 & 25 & 8.442 & 278195 & 2.221 & 1.189 \\
\hline 30 & 3 & 45 & 1.2 & 40 & 4.657 & 227227 & 1.93 & 1.237 \\
\hline
\end{tabular}

It is evident from the above equation (Eq. 1) that variables of $\mathrm{X} 1$ (concentration of acetic acid), X3 (flow rate) and $\mathrm{X} 4$ (column temperature) have a positive effect on retention time, while variable X2 (\% ratio of acetic acid) revealed negative effect to retention time. There was no significant interaction except the interaction between \% ratio of acetic acid and flow rate. This, interaction reduced the retention time and especially observed at the low level of the concentration of acetic acid and column temperature 
(Figure 3.1). Similarly, the proposed models for Y2 (peak area), Y3 (resolution) and Y4 (tailing factor) were as follows:

$$
\frac{1}{\sqrt{Y 2}}=1.979 \times 10-3-3.703 \times 10-6 \mathrm{X} 1+2.154 \times
$$

$10-5 \mathrm{X} 2+1.795 \times 10-4 \mathrm{X} 3+2.833 \times 10-5 \mathrm{X} 4+2.856 \mathrm{x}$ $10-6 X 1 \times 2-1.973$ x 10-5X1X3 -5.913 x 10-6X1X4 $4.177 \times 10-6 \times 2 \times 3+1.648 \times 10-5 \times 2 \times 4-6.028 \times 10-$ $6 \mathrm{X} 3 \mathrm{X} 4+9.037 \times 10-7 \mathrm{X} 12+1.226 \times 10-5 \times 22-1.369 \times$
10-5X32 -3.304 x 10-6X42 (Adj. R2 of 0.9836) (Eq. 2)

$\mathrm{Y} 3=2.52+5.625 \times 10-3 \mathrm{X} 1+0.63 \mathrm{X} 2-0.096 \mathrm{X} 3$ $+0.15 \mathrm{X} 4-1.187 \times 10-3 \mathrm{X} 1 \mathrm{X} 2-1.812 \times 10-3 \mathrm{X} 1 \mathrm{X} 3-$ $6.687 \times 10-3 \mathrm{X} 1 \mathrm{X} 4-8.437 \times 10-3 \mathrm{X} 2 \mathrm{X} 3+0.072 \mathrm{X} 2 \mathrm{X} 4$ $+6.313 \times 10-3 \times 3 \times 4+0.017 \times 12+0.050 \times 22+7.656 \times$ 10-3X32 -0.010X42 (Adj. R2 of 0.9954) (Eq. 3)<smiles>COc1cc(/C=C/C(=O)CC(=O)/C=C/c2ccc(O)c(OC)c2)ccc1O</smiles><smiles>COc1cc(/C=C/C(=O)CC(=O)/C=C/c2ccc(O)c(O)c2)ccc1O</smiles>

Figure 1. Chemical structures of curcumin (CUR) and demethoxycurcumin (DMC).

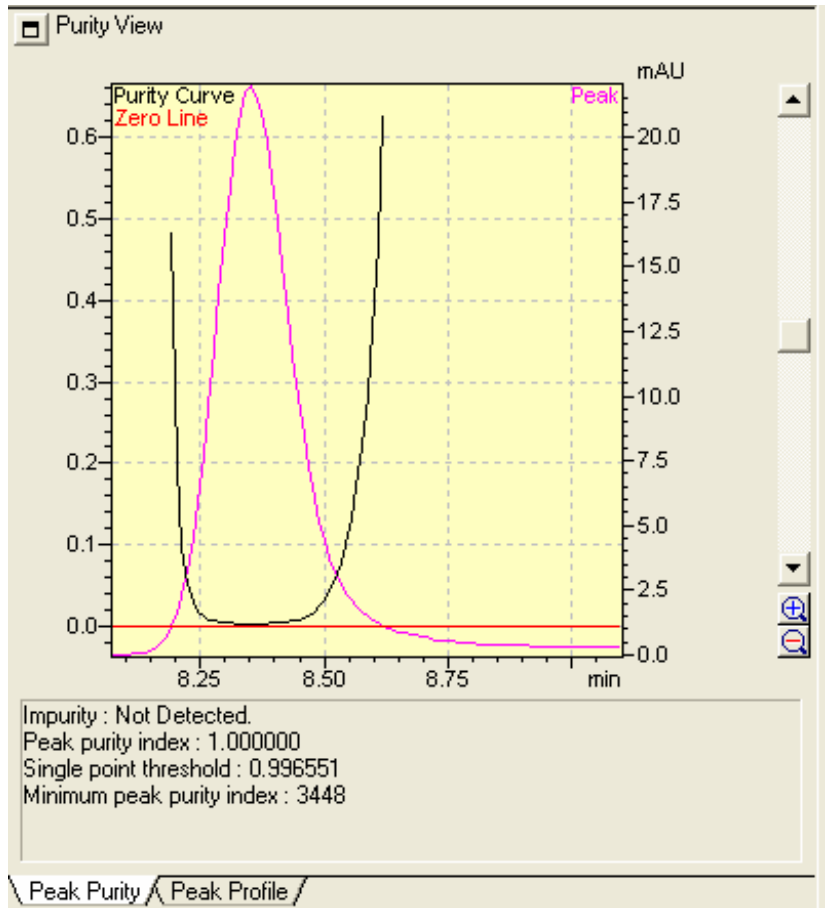

Figure 2. Peak purity of CUR standard in one of experimental design run. 
I

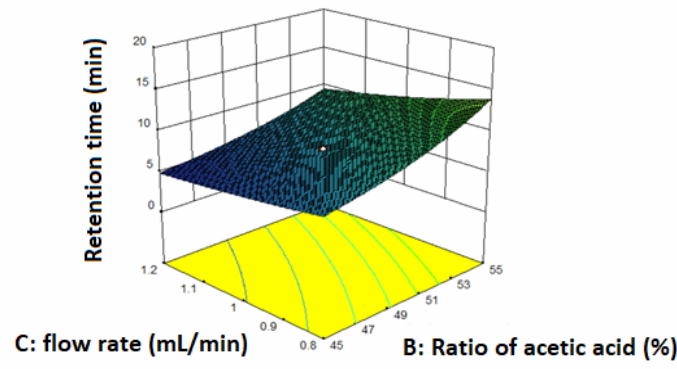

(III)

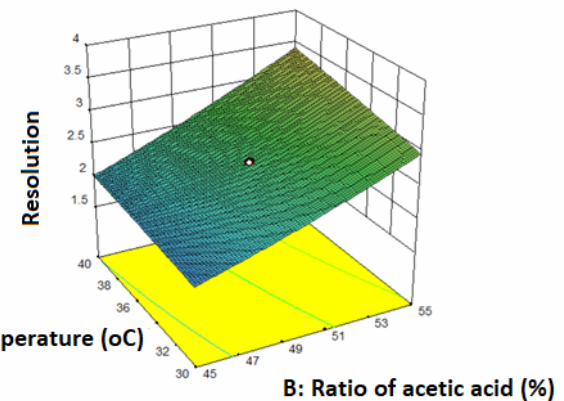

(II)

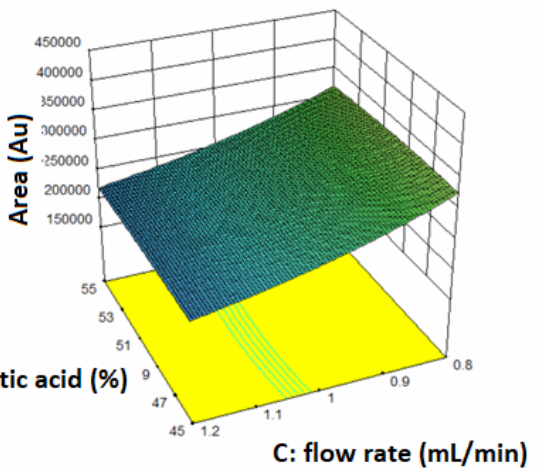

(IV)

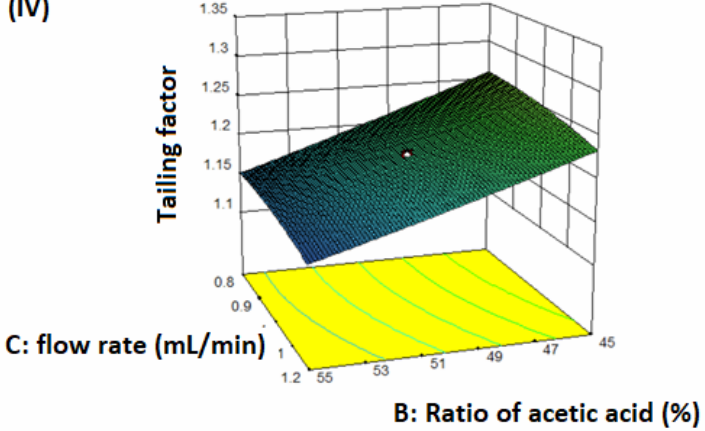

Figure 3. 3-D surface plots for retention time (I), peak area (II), resolution (III) and tailing factor (IV).

$\mathrm{Y} 4=1.20-0.016 \mathrm{X} 1-0.052 \mathrm{X} 2-0.011 \mathrm{X} 3+4.375$ x 10-3X4 -8.125 x 10-4X1 X2+1.875 x 10-4X1X3 $1.312 \times 10-3 \mathrm{X} 1 \mathrm{X} 4+2.938 \times 10-3 \mathrm{X} 2 \mathrm{X} 3-2.312 \times 10-$ $3 \mathrm{X} 2 \mathrm{X} 4-4.062 \times 10-3 \mathrm{X} 3 \mathrm{X} 4+0.014 \mathrm{X} 12+1.844 \times 10-$ $3 \mathrm{X} 22-5.531 \times 10-3 \mathrm{X} 32-3.406$ x 10-3X42 (Adj. R2 of 0.8058$)$ (Eq. 4).

The effect of independent variables on peak area was depicted on Eq. 2. Acetic acid concentration did not have significant effect on peak area $(p>0.05)$, while the other variables (\% ratio of acetic acid, flow rate, and column temperature) had significant effect $(\mathrm{p}<0.05)$. Interaction between acetic acid concentration and flow rate or $\%$ ratio of acetic acid and column temperature had significant value. These interactions were observed especially from the middle to high level of flow rate (Figure 3.II) and low to middle level of \% ratio of acetic acid. Eq. 3 depicts the effects and interactions of independent variables on resolution. The \% ratio of acetic acid had higher significant effect on increasing the resolution than that of column temperature, while flow rate reduced the resolution. In addition, an interaction was observed between \% ratio of acetic acid and column temperature. Furthermore, in order to elucidate this interaction deeply, 3D surface plot of resolution was presented in figure 3 III. It revealed that increasing the $\%$ ratio of acetic acid under different level of column temperature had different resolution value.

Multiple linear regression analysis (MLRA) of tailing factor has been presented in Eq. 3. This model had bad fitting due to high difference between Adj. R2 and Pred. R2. Therefore, a verification step was required to ensure the model could be used to predict the tailing factor response adequately. However, the whole of this design space had acceptable tailing factors ranging from 1.116 to 1.348 (less than 1.5). Thus, this response had negligible effect on determining the optimized condition. Based on Eq. 3, an increase in \% ratio and concentration of acetic acid had significant effect on reducing the resolution. Although, the effect of $\%$ ratio of acetic acid was higher than that of the acetic acid concentration. 

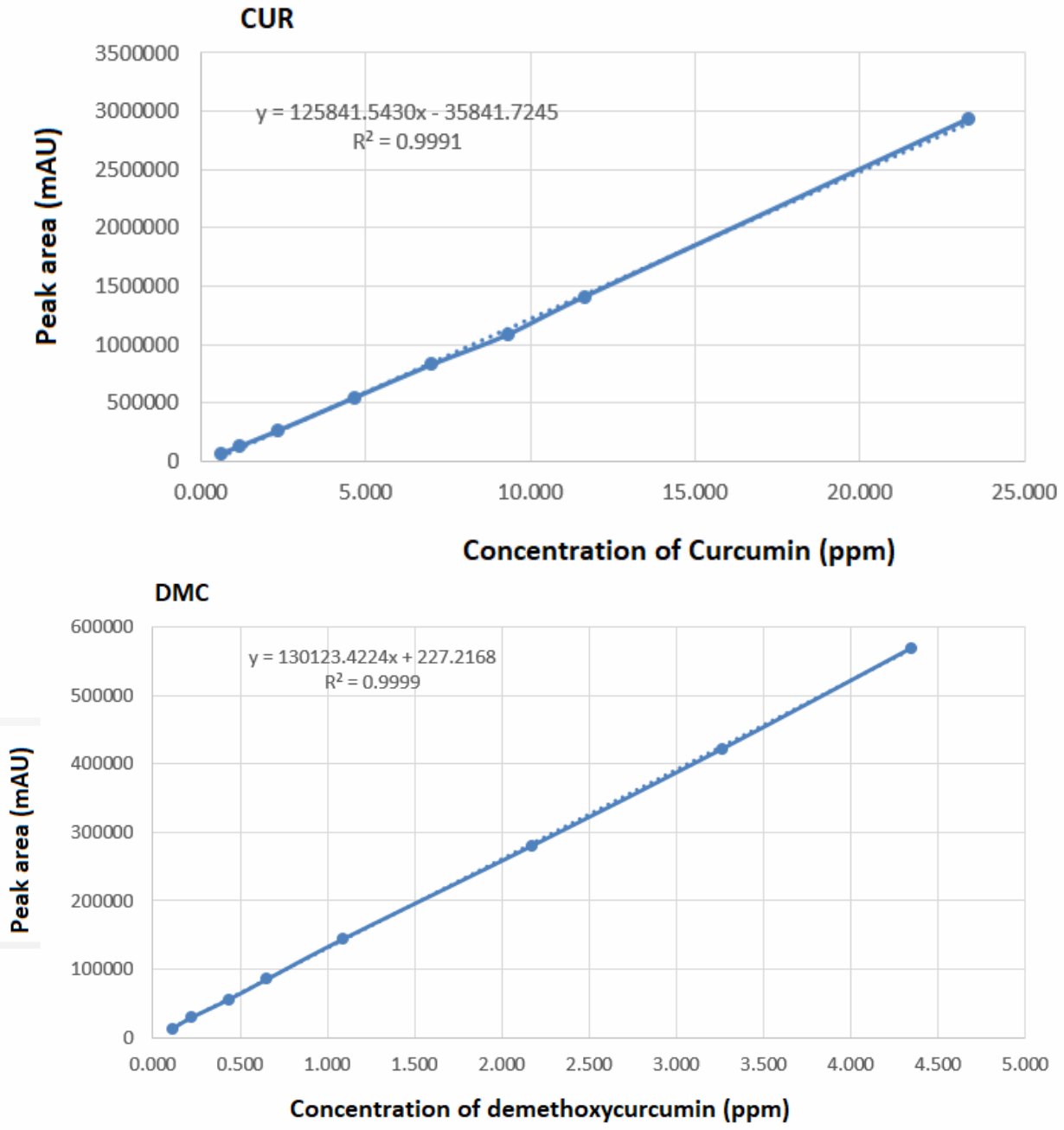

Figure 4. Calibration plot for relationship between concentration of curcumin (CUR) and demethoxycurcumin (DMC) with peak area.

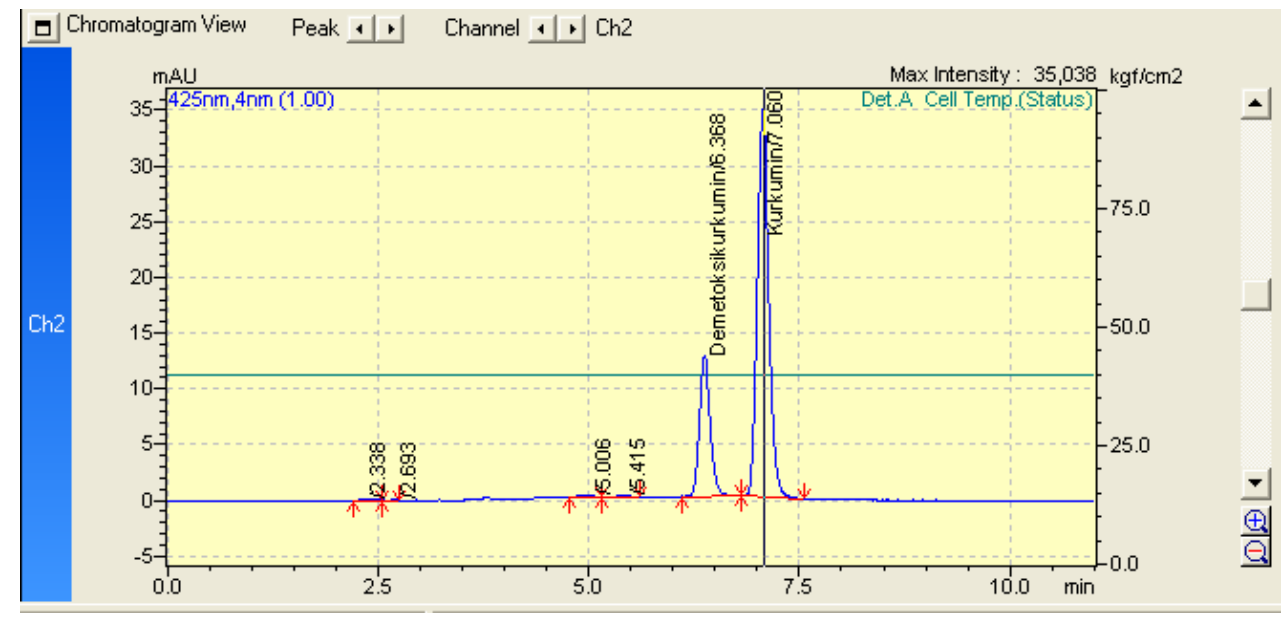

Figure 5. Typical HPLC chromatogram of tablet samples using optimized condition (see text for optimized HPLC condition). 
Figure 3.IV showed that an increase of the $\%$ ratio of AA at different level of column temperature linearly increased the tailing factor. In addition, there was no significant interaction observed in this model.

In order to determine the control strategy of optimized condition from design space, superimposed contour plot of several contour plots of responses was applied. This determined depending on the quality target of condition which is presented in table 2. The optimized condition was obtained at concentration of acetic acid of $3 \%, \%$ ratio of acetic acid of 51.303 , flow rate of $1.048 \mathrm{ml} / \mathrm{min}$ and column temperature of $45^{\circ} \mathrm{C}$.

Validation of HPLC method. Before validation of HPLC method, system suitability test (SST) was performed. United Stated Pharmacopeia (USP) recommends some parameters to be evaluated namely retention time, peak height, peak area, width, tailing factor, the number of theoretical plate and high equivalent of theoretical plate (HETP). The precision, expressed as \% relative standard deviation (RSD) of the separameters were less than $2 \%$, indicating the suitability of HPLC system used for determination of CUR and DMC.

The optimized condition of HPLC method was validated according to guidance set by ICH 19 by determining several validation parameters, namely selectivity, linearity, precision, accuracy, limit of detection and limit of quantification. The selectivity evaluation of HPLC method was performed by injecting solvents (mobile phase), CUR, DMC and the binary mixture of CUR and DMC. The method was selective because the peaks of CUR and DMC were well separated with resolution (Rs) value of $\geq$ 2.0. The linearity evaluation of CUR and DMC was assessed by preparing 8 standards solution with different concentrations $(0.583-23.311 \mu \mathrm{g} / \mathrm{ml}$ for CUR and $0.109-4.348 \mu \mathrm{g} / \mathrm{ml}$ for DMC). The calibration curve exhibited good relationship of analytes (x-axis) and peak area (y-axis) with $\mathrm{r}$-value of $>0.999$ for both analytes (Figure 4). Using linear regression obtained, the values of limit of detection (LOD) and limit of quantification (LOQ) were 0.126 and $0.382 \mu \mathrm{g} / \mathrm{mL}$ for CUR, and $0.074 \mu \mathrm{g} / \mathrm{ml}$ and $0.223 \mu \mathrm{g} / \mathrm{ml}$ for DMC.

Intra-day precision (repeatability) exhibited acceptable values of relative standard deviation (RSD), i.e. $0.53 \%$ for CUR and $0.90 \%$ for DMC. These RSD values were lower than those of RSD Horwitz, in which at concentration level of $1 \%$ of target analytes, RSD Horwitz was 4\%. ${ }^{22}$ The recovery percentages of CUR and DMC for accuracy study were in the acceptable range according to $\mathrm{ICH}$ guideline. The recovery values were in the range of 101.56-103.78\% for CUR and 99.02-99.96\% for DMC. No bias more than 5\% was observed. RSD and recovery values indicated precise and accurate HPLC method for analysis of CUR and DMC in tablet formulation.

Assay of CUR and DMC in tablets. Validated HPLC method was used for simultaneous analysis of CUR and DMC in tablet formulation containing Curcuma extract. The concentration of CUR and DMC in tablet samples were $3.09 \pm 0.02 \mathrm{mg} /$ tablet (CUR) and $0.22 \pm 0.002 \mathrm{mg} /$ tablet (DMC). The typical HPLC chromatogram of samples was shown in figure 5. No interfering peaks were observed. This indicated that there was no interference from the excipients used in tablets. The RSD values obtained were less than $1 \%$ in all case.

\section{CONCLUSION}

Central composite design using four optimum factors namely concentration of acetic acid $(3.00 \%)$, ratio of acetic acid (51\%), flow rate of mobile phase $(1.05 \mathrm{ml} / \mathrm{min})$ and column temperature $\left(45^{\circ} \mathrm{C}\right)$ was successfully used to get optimum condition of HPLC method for analysis of CUR and DMC in tablet samples. All validation parameters of HPLC met the acceptance criteria according to ICH guidelines.

\section{ACKNOWLEDGEMENTS}

The author thanks to Ministry of Research and Higher Education for financial support during this research via scheme Penelitian Unggulan Perguruan Tinggi 2017 with contract number 807/UN1P.III/LT/DIT-LIT/2017. 


\section{REFERENCES}

1. Devaraj, S., Ismail S., Ramanathan, S. and Yam, M.F. 2014. Investigation of antioxidant and hepatoprotective activity of dtandardized curcuma xanthorrhiza rhizome in carbon tetrachloride-induced hepatic damaged rats. The Sci. World J.,Volume 2014; Article ID 353128. 8 pages. http://dx.doi.org/10.1155/2014/353128.

2. Ambarsari, L., Nurcholis, W., Darusman, L.K., Mujib, M.A. and Heryanto, R. 2014. The curcuminoids extract of Curcuma xanthorrhiza roxB. Loaded solid lipid nanoparticles. Int. J. Sci. Res. 3, 352-358.

3. Lantz, R.C., Chen, G.J., Solyom, A.M., Jolad, S.D. and Timmermann, B.N. 2005. The effect of turmeric extracts on inflammatory mediator production. Phytomedicine. 12, 445452

4. Hwang, J.K., Shim J.S., Baek N.I. and Pyun Y.R. 2000. Xanthorrhizol: a potential antibacterial agent from curcuma xanthorrhiza against streptococcus mutans. Planta Med. 66, 196-207.

5. Tanaka, K., Kuba, Y., Sasaki, T., Hiwatashi, F. and Komatsu, K. 2008. Quantitation of curcuminoids in curcuma rhizome by near-infrared spectroscopic analysis. J. Agric. Food Chem. 56, 8787-8792.

6. Rohman, A., Sudjadi, Ramadhani, D. and Nugroho, A. 2015. Analysis of curcumin in Curcuma longa and Curcuma xanthorriza using FTIR spectroscopy and chemometrics. Res. J. Med. Plant. 9, 179-186.

7. Péret-Almeida, L., Cherubino, A.P.F., Alves, R.J., Dufossé, L. and Glória, M.B.A. 2005. Separation and determination of the physico-chemical characteristics of curcumin, demethoxycurcumin and bisdemethoxycurcumin. Food Res. Int. 38, 1039-1044.

8. Nugroho, A., Rohman, A., Lukitaningsih, E., Rakhmawati, N. and Sudjadi, S. 2015. Analysis of curcumin in ethanolic extract of Curcuma longa Linn. and Curcuma xanthorriza Roxb. Using high performance liquid chromatography with UV-Detection. Res. J. Phytochem. 9, 188-194.

9. Syed, H.K., Liew, K.B., Loh, G.O.K. and Peh, K.K. 2015. Stability indicating HPLC-UV method for detection of curcumin in curcuma longa extract and emulsion formulation. Food Chem. 170, 321-326.

10. Inoue, K., Nomura, C., Ito, S., Nagatsu, A., Hino, T. and Oka, H. 2008. Purification of curcumin, demethoxycurcumin and bisdemethoxycurcumin by high-speed countercurrent chromatography. J. Agric. Food Chem. 56, 9328-9336.
11. Asai, A. and Miyazawa, T. 2000. Occurrence of orally administered curcuminoid as glucuronide and glucuronide/sulfate conjugates in rat plasma. Life Sci. 67, 2785-2793.

12. Jiang, H., Somogyi, A., Jacobsen, N.E., Timmermann, B.N. and Gang, D.R. 2006.Analysis of curcuminoids by positive and negative electrospray ionization and tandem mass spectrometry. Rapid Comm. Mass spectrom. 20, 1001-1012.

13. Anderson, M.J. and Patrick, J.W. 2004. RSM Simplified: Optimizing Processes Using Response Surface Methods for Design of Experiments. CRC Press Taylor and Francis Group, New York.

14. Monks, K.E., Rieger, H.-J. and Molnar, I. 2011. Expanding the term "Design Space" in high performance liquid chromatography. J. Pharm. Biomed. Anal. 56, 874-879.

15. Paulucci, P.V., Couto, R.O., Teixeira, C.C.C. and Freitas, L.A.P. 2012. Optimization of the extraction of curcumin from Curcuma longa rhizomes. Br. J. Pharmacog. 23, 94100.

16. Sogi, D. S., Sharma, S., Oberoi, D. P. S. and Wani, I. A. 2010. Effect of extraction parameters on curcumin yield from turmeric. J. Food Sci. Technol. 47, 300-304.

17. Avram, M., Stroescu, M., Stoica-Guzun, S., Floarea, O. and Dobre, T. 2015. Optimization of curcumin extraction from turmeric powder using a box-behnken design (BBD). REV. CHIM. 66, 79-82.

18. Dawud, E.R. and Shakya, A.K. 2014. HPLC-PDA analysis of ACE-inhibitors, hydrochlorothiazide and indapamide utilizing design of experiments. Arabian J. Chem. http://dx.doi.org/10.1016/j.arabjc.2014.10.052

19. International conference on harmonisation. 2005. Validation of analytical Procedures: Text and methodology.

20. Ira, S.K. and Michael, E.S. 2001. Determining specificity in a regulated environment. LCGC. 19, 604-614

21. Ainurrofiq, A. and Choiri, S. 2016. Development and optimization of a meloxicam/ $\beta$-cyclodextrin complex for orally disintegrating tablet using statistical analysis. $J$. Pharm. Dev. Technol. doi: http://dx.doi.org/10.1080/ 10837450. 2016.1264418

22. González, A.G. and Herrador, M.Á. 2007. A practical guide to analytical method validation, including measurement uncertainty and accuracy profiles. TrAC Anal. Chem. 26, 227-238. 